\title{
Missão do advogado no mundo contemporâneo *
}

\author{
Miguel Reale \\ Catedrático đe Filosofia do Direito na \\ Faculdade de Direito da Universidade \\ de São Paulo.
}

Os bacharéis no pelourinho

No último quartel do século passado, o ilustre médico paulista, Luís Pereira Barreto, adepto fervoroso das idéias mestras de Augusto Comte, escrevia uma longa introdução ao segundo volume de seu livro As três filosofias, dedicando-as "aos legistas".

Foi essa, talvez, a primeira objurgatória lançada no Brasil contra os pretensos males do "bacharelismo" ou da "bacharelice" na vida cultural e política do País.

É sabido que Augusto Comte não teve uma compreensão plena e segura do fenômeno jurídico, tendo sido o seu espírito dominado por um determinado tipo de Ciểncia do Direito e por uma determinada espécie de jurista: o filósofo de Montpellier tinha diante dos olhos uma Jurisprudência formalista e convencional, enclausurada no mundo dos conceitos e dos silogismos, distante das mutações sociais, por

* Tese apresentada à II Conferência Nacional de Advogados, realizada em São Paulo, de 5 a 11 de Agôsto de 1960, com as conclusões então unânimemente aprovadas. 
fôrça de sua fundamental inspiração racionalista e abstrata. Pelas mesmas razões não concebia êle o jurista senão como um "leguleio" divorciado das realidades humanas, apegado em demasia ao casuismo, perdido no sonho de subordinar o devir histórico a regras esteriotipadas e frias.

Em sua justa reação contra o abstratísmo do século xvir e, de certa forma, contra a Metafísica racionalista tradicional, Augusto Comte fazia uma identificação perigosa entre o jurisperito e o amante mais das aparências do que da realidade.

Foi sob o impacto dessas idéias que Luís Pereira Barreto formulou a sua crítica amarga, não só apontando as Faculdades de Direito do país como fontes perniciosas de ensinamentos inúteis, como proclamando a decadência do bacharel, para a ascenção progressiva e segura dos cultores das ciências exatas.

No seu modo de ver, o fim da era dos bacharéis já soara, por ter-se exaurido o momento da especulação nietafísica, cuja finalidade consistira apenas em superar a fase primitiva das crenças e dos temores teológicos.

Com uma confiança desmedida na verdade de sua tese, concluía afirmando que os próprios cultores da Jurisprudência já estavam convencidos de seu malogrado destino, conformados com a perda irremediável de um primado social, prestes a passar, definitivamente, das mãos dos "fazedores de leis" para as mãos dos "descobridores de leis" imanentes nos fenômenos naturais. Anunciava êle, todavia, embora com muita imprecisão, o advento de uma atividade jurídica nova, subordinada às ciências positivas, notadamente à Sociologia, momento compreensivo e culminante de todos os saberes humanos.

\section{II}

Volvidas cerca de nove décadas, as ponderações de Luís Pereira Barreto ainda se me afiguram merecedoras de nosso estudo, especialmente em virtude do que, nesse 
meio tempo, foi dito e se continua a dizer contra o bacharel e, de maneira particular, contra o advogado, apontado por muitos como o principal responsável por todos os males da República.

Criou-se no Brasil uma figura falsa do bacharel, geralmente confundido com o homem que prefere a verossimilhança à verdade; capaz de esvaziar as palavras de seus conteúdos mais fecundos, num jôgo floral de símbolos insignificantes; pouco af eito à compreensão concreta da existência humana, pelo hábito de subordinar, artificialmeñte, os acontecimentos cotidianos, por mais revolucionários e imprevistos, aos mesmos esquemas normativos estiolados; seduzido mais pela beleza extrínseca das coisas do que pela verdade oculta nas fôrças reais que condicionam o viver social; mais levado a transigir, aceitando acomodações provisórias, do que disposto a afrontar, com perseverança e método, os obstáculos opostos ao progresso social; mais propenso a reproduzir e a copiar modelos alienígenà $\mathrm{doo}$ que a fundir imagens novas no cadinho da experiência própria.

Foram, sobretudo, alguns sociólogos, por sinal bacharéis, que mais se empenharam em acentuar os traços caricaturais do bacharelismo, com o qual se quis identificar tôda uma época da vida brasileira, considerada, afoitamente, convencional e postiça, só por não andarem ainda em voga expressões que hoje em dia parecem constituir o prato cotidiano da opinião pública, como "realidade brasileira", "desenvolvimento" ou "auto-consciência nacional".

Estão todos lembrados que foi sobretudo logo após a Revolução de 1930 que se exacerbou a crítica aos bacharéis em Direito, como se êles, com o seu amor ou apêgo aos sistemas normativos, constituissem um empecilho ao despertar da nacionalidade. Em certos círculos chegou-so mesmo a contrapor o "bacharel", símbolo urbano da República velha, ao "tenente", ardoroso desbravador de uma nova era republicana, aderente à "realidade brasileira", como antes havia sido contrapośto ao "coronel", expressão da mentalidade rural e tradicionalista. 
Os juristas passaram a ser vistos como meros "assessôres" dos líderes políticos, com a incumbência subordinada de conferir forma e figura aos planos governamentais, perdida a visão de conjunto, que é condição primordial de êxito nas atividades do Estado. Esquecia-se, por outro lado, da impossibilidade de se conceberem "problemas de fundo" desligados dos "problemas de forma", quando, na realidade, o estadista não ignora que o sucesso da ação estatal, em um Estado de Direito, depende da arte de fundir instrumentos jurídicos de trabalho em imediata consonância com os objetivos visados e os "meios materiais de ação". É a razão pela qual os homens da lei devem participar, ativa e criadoramente, dos planos de govêrno, em pé de igualdade com os mentores da coisa pública, qualquer que seja a sua formação profissional ou técnico-científica.

Resta, pois, saber até que ponto uma crítica apressada e superficial do papel do advogado no seio da nacionalidade não terá contribuído para esvaziá-la de "senso jurídico", que é senso de medida e de proporção.

Parece-me, por conseguinte, oportuno e mesmo inadiável debater êsse grave problema num Congresso Nacional de Advogados, muitò embora, à primeira vista, possa a questão parecer distante das preocupações de ordem profíssional. Na realidade, porém, tôda profissão constitui um status social, denota um conjunto orgânico de circunstâncias inseparável da pessoa que a exerce.

Se, como diz Ortega y Gasset, "eu sou eu e as minhas circunstâncias", não é demais que o advogado medite um pouco sôbre a dimensão humana que êle julga possuir e aquela que certa gente lhe atribui. Por outro lado, é tão sòmente graças a essa prévia tomada de consciência do próprio status social que se tornará possível aos advogados situar, com maior segurança, os problemas particulares oriundos do exercício de seus misteres, captado o sentido mais penetrante e vivo de certas perguntas e descortinadas perspectivas que só a visão do todo propicia.

Nenhuma profissão, como a do advogado, está tão ligada aos problemas existenciais do homem. Se o Direito não 
é tudo, é, todavia, condição primordial para que, na comunidade dos homens, surjam e se desenvolvam as atividades mais diversas, a começar pela revelação de cada homem enquanto homem, segundo os seus pendores naturais, protegidos pelo escudo das liberdades políticas e civis.

\section{III}

\section{Perspectivas históricas}

Nesse exame de consciência de nossa profissão, devemos partir, em primeiro lugar, de certas perspectivas históricas, afim de pôr um paradeiro à tola pretensão de um primado social ou político, que teríamos perdido em determinado momento do processo histórico: não o perdemos pela simples razão de que, enquanto advogados, nunca o tivemos.

Não há dúvida que há certas épocas em que a missão do jurista e do advogado se mostra mais operante, projetando-se mais fortemente no cenário das inquietações humanas: tal acontece sobretudo nas épocas em que a humanidade procura consubstanciar em leis e em códigos o resultado de suas penosas conquistas; ou, então, quando se arma de um punhado orgânico de normas como instrumento indispensável a novas conquistas.

A história de Roma está aí para ensinar-nos que os homens da lei não se colocam necessàriamente à margem da vida, destituídos de qualquer influência positiva no desenrolar dos acontecimentos sociais. Sabe-se melhor, hoje em dia, que o Direito Romano clássico não teria surgido se, antes do pretor, que armava de "imperium" as suas decisões, não tivesse existido a figura serena e criadora do jurisconsulto, verdadeiro mentor da Ciência jurídica e da jurisdição, quase sempre cidadão atuante nas primeiras linhas da história da República. 
Depois, quando o patrimônio cultural dos Romanos. ameaçava ser submerso pelas ondas das invasões externas e das subverções intestinas, foram ainda os jurisconsultos que esculpiram, no bronze do Digesto, as lições de um milênio de história, com uma precisão que Leibniz comparavaà verdade das matemáticas.

A obra dos jurisconsultos de Justiniano, por mais procedentes que possam ser as criticas dos interpolacionistas, ávidos de desvendar os arcanos do Direito romano clássico, constitui um monumento de tal magnitude que a êles se deve, talvez, um dos fáceis desvios a que se entregam alguns bacharéis: o esquecimento da realidade viva pelo deslumbramento formal dos textos.

Como, porém, culpar Papiniano dos equívocos de seus exegetas? Também no domínio das ciências exatas não faltam exemplos de atrazos e crises motivados pela reverência a ídolos e ideologias.

Como estranhar o "culto do Digesto", na época dos glosadores, se êles viam, com acêrto, a correspondência entre o velho Direito justinianeu e as exigências históricas de sua época, preparando manancial preciso de conceitos e de institutos para fundir as matrizes da cultura jurídica moderna? Tão ligados a seu tempo se mostraram êles, os glosadores, que a culta Bolonha ainda ostenta orgulhosamente, em suas praças públicas, as estátuas que denotam a presença participante dos homens da lei na vida social, política e econômica de uma época decisiva para o destino do homem ocidental.

Que adiantariam, em verdade, as afirmações mais revolucionárias das ciências, desde a época dos Descobrimentos até ao dealbar inquietante da era interplanetária, se, ao lado do cientista, não se erguesse a figura do jurista, nâo só consolidando e garantindo o "já realizado", mas preservando, ao mesmo tempo, a liberdade e o direito de inovar, tutelando o infinito "a realizar"?

O certo é que não há autêntica revolução no cosmo dos saberes humanos, assim como no domínio da praxis. 
política, que, em um dado momento, não se deva plasmar em leis, sob pena de se comprometerem as conquistas alcançadas: todo Napoleão orgulha-se de seus Códigos; tôda revolução técnico-científica espelha-se, mais cedo ou mais tarde, num sistema de normas juridicas que lhe consagra valores e perspectivas.

Tais correlações não devem causar surprêsa, pois o Direito é uma das dimensões universais e permanentes do ser do homem, e, como tal, constitui uma expressão da vida humana, como fator que é do "mundo da cultura", em unísono com os demais fatôres que refletem e potenciam os valores instituidores do Espirito tais como as Artes, a Economia, e as Ciências. Daí a natural vibratilidade do jurista pelas mais diversas expressões da ação humana, nelas lobrigando motivos de complementariedade e de equilíbrio.

O ordenamento jurídico, que se não deve confundir com o sistema das leis, é como que o retrato antecipado dos possíveis comportamentos humanos, razão pela qual ao advogado, mais do que a qualquer homem, se aplica a eterna lição de Terencio: "Homo sum: nihil humani a me alienum puto".

A advocacia é, em suma, uma profissão cujas raizes se aprofundam numa compreensão humanista, cuja natureza é, mais do que nunca, merecedora de nosso diálogo, da troca de idéias que, desde Platão, é a forma por excelência do filosofar.

\section{IV}

\section{Atualização do preparo científico}

Assentes os pressupostos do problema, cabe-nos perguntar que poderá haver de específico e de novo na missão do advogado nos horizontes do mundo contemporâneo e quais os deveres que êste lhe impõe. 
A primeira verdade, a que se põe de imediato, com a fôrça às vêzes monótona dos truismos, é a de que existe uma "crise do Direito". Esta aî́irmação seria, porém, deveras desalentadora se sòmente o Direito estivesse em crise: na realidade, a chamada "crise de Direito" é apenas um capítulo da crise geral de estrutura de nosso tempo, que vai desde os horizontes aparentemente serenos das Matemáticas ao jôgo cotidiano dos preços dos gêneros de primeira necessidade. Mais uma vez, coma se vê, a demonstraçăo de que o Direito só tem sentido na concretitude do processo histórico, ou por outras palavras, quando considerado em função do sistema global das fôrças em que se insere e com as quais se conjuga.

Sob êsse prisma, não se poderá recusar o acêrto dos que verberam nos juristas certa tendência a viver como homo juridicus, quando só se pode e só se deve viver como homem, na integridade e riqueza de tôdas as nossas valências. Tôdas as setorizações do viver social são equívocas, e até mesmo funestas, provocando, por exempio, distorções e estrabismos como os das cosmovisões fundadas, unilateralmente, só em valores econômicos, só em valores políticos, só em valores estéticos, só em valores religiosos, só em valores científícos. .

O mundo da cultura é solidário, e o Direito, como permanente composição de fôrças em equilíbrio instável, reflete, no mais alto grau e da maneira mais direta, a funcionalidade complementar ou coimplicante dos atos e das obras do homem.

Eis aí o primeiro, o primordial dever que temos como juristas: situarmo-nos no sistema integral das fôrças de nosso tempo, sem perda da visão harmonizadora do conjunto, fora da qual os fatos singulares perdem o seu significado autêntico. Nossa época tem sêde de concretitude, anceia por soluções integralizadoras, que não mutilem os homens e as coisas.

Dentro dessa compreensão concreta e total, necessàriamente plurivalente e plurimetódica, é evidente que as leis, 
ou, de maneira mais ampla, as normas jurídicas deixam de valer em si e por si, como se fôssem figuras geométricas, abstratas e frias, para serem antes consideradas instrumentos plásticos de vida, e, mais precisamente ainda, "momentos de vida", a tal ponto que entre a "norma "e a "situação normada" não se cavem abismos, mas coexistam amb̄os os têrmos na unidade dialética de um único processo.

A nós advogados cabe travar esta batalha decisiva em prol de um Direito que, sem perda dos valores inelimináveis da certeza e da liberdade, assegure uma correspondência cada vez mais efetiva entre a "norma vivida" e as exigências sociais concretas: tal mudança de atitude em face dos problemas dará novo sentido à Ciência do Díreito e acabará por prevalecer sôbre os óbices da rotina, inclusive nos domínios às vêzes esclerosados dos órgãos jurisdicionais.

Mas se queremos e devemos participar das primeiras linhas da dinâmica social, mister é atualizarmos nossa formação científica, não apenas no que se refere à feitura, à interpretação e à aplicação das normas de Direito, mas também pela compreensão filosófica e sociológica dos fenômenos jurídicos, para que se não confunda o Direito com a lei, nem se estabeleça uma desfasagem entre o Direito e as Ciências positivas.

\section{V}

Ł, sem dúvida, a necessidade de maior aderência a interêsses concretos que explica a crescente multiplicidade nas especializações da advocacia. O advogado onisciente, capaz de resolver tôdas as dificuldades jurídicas, do Direito Penal ao Mercantil e Fiscal, torna-se cada vez mais raro, o que é um benefício quando o especialista não se olvida dos problemas gerais e comuns da Ciência do Direito. Se, como disse Lutero, repetido por Carnelutti, o jurista, que é só jurista, é uma pobre e triste coisa, que 
não dizer do penalista que é só penalista, do comercialista que é só comercialista?

No mare magnum das leis e das especialidades urge que saibamos preservar a unidade superior da Ciência e o sentido unitário da "comunidade dos juristas".

Não somos, por certo, só nós os advogados que fazemos as leis, mas não nos esqueçamos de que, de uma forma ou de outra, acabamos sempre sendo responsabilizados por elas... Longe de rejeitarmos essa responsabilidade, devemos recebê-la como um apanágio, um elogio à capacidade plasmadora de nossa inteligência e às reservas éticas de nosso Espírito, visto como a sociedade confia em que o advogado saberá reagir contra as leis más, não só exigindo a sua revogação, como, em sendo elas vigentes, pela arte sutil de lhes polir as arestas, graças ao seu enquadramento no sistema coerente da ordem jurídica total. Essa compreensão harmonizadora do todo, digâmo-lo sem falsa modéstia, é uma das virtudes do bacharel, o que às vêzes o faz ser ou parecer dispersivo e inconstante, de tudo preocupado e por tudo seduzido, sem se fixar em ponto algum, o que pode ocorrer quando se olvida que só a modéstia, companheira serena do estudo objetivo e da disciplina metódica, nos possibilita intuir as linhas reveladoras do todo.

Especializar-se, por conseguinte, é um dos deveres do advogado contemporâneo, mas evitando a deformação própria dos especialistas precoces, envaidecidos de sua técnica, de seus instrumentos conceituais e de seus fichários, aos quais tanto mais se escravizam quanto mais se julgam senhores da mais alta cultura jurídica.

E' a razão pela qual as Faculdades de Direito de maior responsabilidade no panorama cultural do País devem cuidar com carinho de seu Curso de Especialização, tarefa esta mais própria dos institutos universitários oficiais, e tanto mais necessária quanto mais se multiplicam, não raro sem o devido critério, as Escolas de Direito pelo território nacional. 


\section{VI}

\section{o bacharel na vida nacional}

Nossa modéstia não deve, todavia, levar-nos a aceitar, sem os devidos reparos críticos, a responsabilidade que se tem querido atribuir ao bacharel por certos erros de nosso sistema cultural e político.

De tais erros somos responsáveis na medida em que temos tido mais ocasiões de participar das funções de Govêrno, pela própria natureza de nossa formação científica, mas não creio que se possa excluir, em maior ou menor proporção, a responsabilidade dos militares, médicos, engenheiros, economistas, jornalistas, agricultores ou industriais.

Quê é, em suma, que se aduz contra o bacharel, que não seja um reflexo de certas tendências e inclinações naturais de nosso povo? Não havia Faculdades de Direito no País, e já vivíamos, como comunidade de estrutura colonial, com olhos fitos em Portugal, como quem admira um modêlo. Se continuamos a sofrer influências externas, benéficas e inevitáveis, não se esqueça que nos cabe o mérito de termos alargado o número e a extensão dos focos irradiadores da cultura recebida, abrindo as janelas do Espírito para a França, a Alemanha, a Itália, a América do Norte, etc.

Quanto à alegação de que o nosso advogado se contenta com aparência, ou com ouropéis verbais, bastaria lembrar, em contraposição a essa tese, o mérito universalmente proclamado de algumas de nossas leis básicas, como Código Comercial de 1850 e o Código Civil, para não falar na atualidade cultural de um Teixeira de Freitas, de um Paula Batista, de um Pimenta Bueno, de um Laíayette, de um Carvalho de Mendonça ou de um Clovis Bevilaqua, cuja obra se desenrola em uníssono com os problemas práticos e concretos. $\mathrm{E}$ enquanto forem lembrados nomes como os de Campos Sales ou de Rodrigues Alves, para não 
citar senão dois vultos da primeira República, será estultice pensar em falta de senso de realidade por parte dos bacharéis brasileiros.

Nem se diga que Ruy Barbosa se deixou fascinar em demasia pelo verbo, pois só o acusam de ideólogo os que conhecem pela rama, quando não por ouvir dizer, a sua obra de mestre de nosso Direito Público, batalhando, por exemplo, em prol de um federalismo orgânico ou de um municipalismo diversificado e dinâmico, que alguns de seus críticos julgam ser descobertas de última hora.

Apaguem-se da história do Brasil as obras de nossos bacharéis, e quê restará da vida cultural e política do Império e da República? Quê restará de nossas letras, de nosso romance, de nossa oratória, de nosso jornalismo, de nossa historiografia, de nossa poesia? Quê restará do pensamento filosófico sem os bacharéis que se chamaram Tobias Barreto, Sílvio Romero, Farias Brito, Pedro Lessa, João Mendes Júnior, Jackson de Figueiredo, Clovis Bevilaqua?

Mais ainda. Para cúmulo dos paradoxos, muitos dos críticos do bacharelismo se louvam em escritos de bacharéis como Alberto Torres e Oliveira Viana, ou são também bacharéis, mas bacharéis bissextos, de experiência juridica esporádica e rala.

$\mathrm{E}$ se volvermos a atenção ao mundo da agrĩcuítura, do comércio e da indústria, seria fácil lembrar nomes de advogados, cuja existência se confunde com as maiores afirmações de nosso progresso econômico.

O que importa, por conseguinte, é distinguir, na imensa classe dos advogados, os que têm uma concepção formalista e abstrata do Direito e os que concebem a vida jurídica em tôda a dignidade e concretitude de suas expressões. Se algumas críticas procedem contra os primeiros, delas ficam isentos os advogados autênticos, cientes e conscientes de sua alta missão no sistema complexo de interêsses e de aspirações das coletividades humanas. 


\section{VII}

\section{Advocacia e liberdade}

Costumo afirmar que a justiça é uma virtude franciscana, porque sempre destinada à tutela e à salvaguarda dos demais valores sociais. No fundo, ordem social justa é aquela em que cada homem ou grupo de homens esteja em condições de realizar, na medida das conjunturas do tempo e das exigências do todo, o máximo de suas possibilidades, sem resultarem comprometidas as fontes da liberdade instituidora do Espírito.

Eis aí outro ponto essencial: conceber o Direito como "realização da liberdade" só tem sentido quando se estabelece uma implicação essencial entre liberdade e Espírito, repelindo-se todo e qualquer programa de govêrno da sociedade pela subordinação crescente dos homens às coisas, por "coisas" se entendendo não apenas os sêres inanimados e corpóreos, mas também' aquilo que se estiola e se imobiliza, como "quadros", "esquemas" ou "sistemas" rígidos, destacados dos impulsos reais da vida.

Êste é um dos riscos que ameaçam mais tràgicamente o homem: a "burocratização", a "estandardização", a "massificação", em prejuizo das faculdades criadoras e expontâneas, reveladoras do que há de distinto e inconfundivel em cada ser livre.

Nós advogados prezamos o valor dêsse bem irrenunciável, do qual provém a beleza de nossa profissão liberal: não só em nosso escritório particular, mas também nos quadros hierárquicos do Estado e das grandes emprêsas, a que prestemos serviços, nós, os advogados, sabemo-nos livres em nossas opiniões, independentes no formar $e$ defender nossas convicções científicas. Não devemos jamais servir como instrumentos, ao sabor e à mercế das opiniões ou dos propósitos alheios: tanto melhor serviremos aos clientes quanto mais nos decidirmos à luz de convicções livremente brotadas da meditação e do estudo. 
Não é mistério para ninguém que a ordem econồmica atual vai tornando cada vez mais marginal a profíssão autônoma, crescendo, dia a dia, o número dos ad̃vogados que prestam seu trabalho em têrmos de relação de emprêgo público ou privado. Com o correr do tempo, os Escritórios de Advocacia, ante a pressão dos fatôres fiscais e as exigências da racionalização dos serviços, também assumirão feitio mercantil, surgindo como verdadeiras "emprêsas" exploradoras do saber jurídico, o que põe em relếvo o problema da liberdade científica que estamos analisándo.

Saber preservar, carinhosa e heròicamente, o patrimônio moral da liberdade científica, num munơo cađa vez mais mecanizado e uniforme, será uma contribuição de alcance ético para tôda a comunidade, uma forma de parłicipação positiva no esfôrço de preservação de uma cultura humanística, que se não reduz apenas ao "saber de humanidades feito", pois uma cultura de bases estritamente científicas poderá ser "humanista" se o cultor da Ciência não se colocar a serviço das coisas, nem se reduzir a um elo na cadeia dos interêsses transpessoais de uma classe ou do Estado.

\section{VIII}

\section{o Direito e o destino das Ciências}

Esta última consideração leva-nos a examinar uma das mais inquietadoras questões de nossa época: a do destino da ciência e do homem de ciência.

Basta um relance de olhos pelos quadrantes do globo, tanto no Ocidente como no Oriente, para nos convencermos de que a Ciência perde, cèleremente, a sua categoria de "fazer do homem", para tornar-se um "fazer do Estado", ou um "fazer de emprêsa". Por tôda parte a Ciência subordina-se a esquemas imensos de organização borocrática, 
pública ou privada, máxime no concernente aos empreendimentos ligados à energia nuclear.

O grande fato de nossa época, ao qual os juristas não têm emprestado a devida atenção, é a crescente burocratização da atividade científica, dada a necessidade de incalculáveis recursos de haveres e de capitais para atender-se às planificações da Nova Ciência.

Não é apenas a Ciência, mas é o cientista que corre o risco de tornar-se tanto mais materialmente poderoso quanto menos política e èticamente livre. O "sistema", o "enquadramento" ameaça-o por tôda parte, com a tentadora barganha de sua independência por bens materiais e meios propiciadores de pesquisa.

Os homens do Direito, não podemos ficar alheios a êsse drama, pois êle nos atinge diretamente: a escravidão do físico, do químico, ou do biologista será a nossa própria escravidão, pois não podemos nos iludir com a possibilidade de destinos diversos, de submissão e de liberdade, no seio de uma mesma ordem jurídica. É sempre comum e solidária a causa da liberdade do Espírito.

Ora, se a Ciência não pode progredir mais na reclusão heróica dos antigos laboratórios, onde o gênio solitário fazia brilhar a luz de uma hipótese revolucionária; se a Ciência tende a marchar "pari passu" com as grandes estruturas organizadoras, mister é que o jurista volte şua atenção para o estudo dessas estruturas, colaborando com o cientista na delicada tarefa de conjugar "organização" e "liberdade"

Aliás, êsse drama da estatalizaçẫo da vida humana foram os advogados os primeiros a senti-lo em sua própria carne, quando na Rússia soviética pràticamente se destruiu a figura do advogado livre professionista, para concebê-lo enquadrado no sistema do Estado classista, ou em função de exigências burocráticas.

Não é sem motivo que já se apontou uma íntima ligação entre Advocacia e Democracia. Onde não há liberdade, pode haver "juristas" a serviço dos Poderes cons- 
tituídos, mas não haverá advogados: a liberdade do advogado, como se vê, tem como pressuposto a liberdade civil e política da comunidade a que êle pertence.

Chegamos, assim, à conclusão de que a profissão de advogado, por sua própria natureza, é uma expressão da liberdade: é profissão democrática em sua estrutura e em seu destino.

\section{IX}

Concepção do Direito e concepção do mundo

Através das páginas aqui rascunhadas quis acenar para os deveres primordiais do advogado como homem, como cientista e como cidadão, e vejo que tudo se resume em ter-se esta ou aquela outra concepção do mundo e, por via de consequência, esta ou aquela concepção do Direito.

Ou se opta por um regime social e político, em que os homens se conservem e se desenvolvam como sêres livres, capazes de querer aficazmente algo não querido pelos que governam, ou então se prefere uma ordem estatal que nos possa dar bens de vida e de confôrto, privando-nos do "luxo da liberdade": no primeiro caso, a advocacia continuará a existir, como profissão que só viceja entre homens livres; no segundo caso, reduzir-se-á a uma função burocrática, assim como o Direito perderá a sua densidade ética, para reduzir-se a um sistema de pesos e contrapesos administrativos.

Não ignoro que os "dois mundos" atuais, por mais que pareçam irremediáveis e iminentes os conflitos, tendem cada vez mais a exercer uma influência recíproca e benéfica, a exemplo do que nos ensinam outros períodos históricos. Situados em condições de contemplar, mais objetiva e serenamente, os dados e os fatôres do formidável embate, talvez nos caiba, a nós brasileiros, maior parcela de responsabilidade na tarefa de antecipar, segundo as 
proporções de uma justiça social concreta, as linhas tranquilizadoras do mundo de amanhã.

O desejo, porém, de mútuo entendimento não poderá jamais representar o sacríficio dos valores de liberdade e de respeito ético à pessoa humana, que estão no cerne de nossa civilização: nesse ponto, que é o essencial, não há lugar para abdicações, nem para renúncias.

Será mister optar entre dois caminhos. É na verticalidade dessa opção que se polariza o que somos e o que podemos ser como homens, como cidadãos e como advogados.

Daí ser possível e mesmo imprescindível oferecer, a guisa de conclusões, os seguintes Enunciados:

$1^{\circ}$ - O advogado deve preservar, contra tudo $e$ contra todos, o cunho liberal e humanista de sua profissão: liberal porque fundada na liberdade de convicção científica; humanistica, porque tem como fundamento a dignidade da pessoa humana e a livre afirmação das infinitas tendências $e$ inclinações do homem;

2. - $O$ advogado deve travar, sem desfalecimento, a luta contra o formalismo jurídico, para a captação autêntica do Direito, não só graças ao sucedâneo filosófico $e$ sociológico da experiência jurídica, como também pela atualização dos elementos categoriais e técnicos peculiares ao pensar jurídico;

$3^{\circ}$ - Torna-se indispensável que os Poderes Públicos reconheçam incontinenti a necessidade de serem instituídos Cursos de Es- 
pecialização de caráter complementar, reclamados pela cultura juridica do País;

4..$^{\circ}$ - advogado deve assumir posiçâo vigilante e ativa no momento da feitura das leis, para preservar-se o caráter técnico da obra legislativa;

$5^{\circ}$ - $O$ mundo contemporâneo exige cada vez mais a contribuição do advogado para a solução dos problemas da organização das atividades científicas e econômicas, afim de que o Estado ou as emprêsas privadas, ao propiciarem os meios materiais indispensáveis à pesquisa científica, não comprometam as liberdades fundamentais do homem;

6. ${ }^{\circ}$ - $O$ advogado deve atuar no mundo contemporâneo com a plena consciência de que só há um regime político-compativel com a sua profissão: o que assegura aos indivíduos $e$ aos grupos as liberdades civis $e$ politicas;

$7^{\circ}$ - O advogado deve, acima de tudo, capacitar-se de que a sua profissão não se exaure num círculo restrito de interêsses pessoais, mas constitui um elemento-substancial da comunidade concreta dos homens que trabalham e realizam valores sociais.

São Paulo, Agôsto de 1960 